\title{
PERBEDAAN KECEMASAN PADA PASIEN YANG AKAN MENJALANI OPERASI BESAR SEDANG DAN KECIL
}

\section{Difference of Anxiety in the Patient Will Running Large and Small Operations}

\author{
Lermiana Br. Purba', Muchti Yuda Pratama', Ade Irma Khairani ${ }^{3}$ \\ ${ }^{1.2 .3}$ Dosen Akademi Keperawatan Kesdam I/BB Medan \\ Email : yudamuchti@yahoo.co.id
}

\begin{abstract}
Abstrak
Penelitian ini bertujuan untuk melihat perbedaan kecemasan pada pasien yang akan menjalani operasi besar, sedang, dan kecil di Rumah Sakit Putri Hijau Medan. Sejalan dengan teori yang ada, dilakukan uji validitas dan reliabilitas pada uji validitas alat ukur, ternyata yang valit 46 butir dan berdasarkan perhitungan derajat reliabilitasnya adalah sebesar 0.969. Alat ukur yang digunakan dalam penelitian ini memiliki tingkat keterandalan yang tinggi (sangat reliable). Untuk bisa menganalisis data penelitian ini dilakukan uji asumsi yaitu dengan uji normalitas sebaran dan uji homogenitas kelompok.

Berdasarkan uji normalitas sebaran dengan perhitungan kosmogorov-smirnov menunjukkan data penelitian yang dianalisis memiliki sebaran yang normal yang ditunjukkan oleh koefisien K-S sebesar 0.122 dengan $\mathrm{P}>0.05(\mathrm{P}=$ 0.089) ketiga kelompok yang digunakan dalam penelitian ini adalah homogeny dengan koefisien homogenitas sebesar 2.724 dengan $\mathrm{P}>0.05(\mathrm{P}=0.077)$.

Perhitungan analisis data yang digunakan dalam penelitian ini adalah analisis statistic anava satu jalur. Ternyata menunjukkan ada perbedaan kecemasan yang sangat signivikan diantara pasien yang akan menghadapi operasi besar, sedang, dan kecil, yang ditunjukkan oleh koefisien $\mathrm{F}=17.385$ dengan $\mathrm{P}<0.01(\mathrm{P}=0.00)$. Ternyata pasien yang akan menjalani operasi besar mengalami kecemasan sebesar 103.73, Sedang 100.07, kecil sebesar 96.20.
\end{abstract}

Kata kunci : Perbedaan cemas operasi kecil sedang dan besar

\begin{abstract}
This study aims to look at the differences in anxiety in patients undergoing major surgery, medium, and small at the Hospital of Putri Hijau Medan. In line with the existing theory, to test the validity and reliability on the test the validity of measuring instruments, it turns out that valit 46 grain and based on the degree of reliability is equal to 0969. Measuring instrument used in this study had a high level of reliability (very reliable). To be able to analyze the data of this study tested the assumption that the distribution normality test and homogeneity test group. Based on the test normality distribution calculation kosmogorov-Smirnov shows research data analyzed has a distribution that is normally indicated by coefficient $\mathrm{KS}$ of 0.122 with $\mathrm{P}>0.05(\mathrm{P}=0089)$ three groups were used in this study is homogeneous with a coefficient of homogeneity of 2,724 with $\mathrm{P}>0.05(\mathrm{P}=0.077)$. Calculation of data analysis used in this research is the statistical analysis ANOVA one lane. Turns showed no differences were very signivikan anxiety among patients who will face major surgery, medium, and small, which is indicated by coefficient $\mathrm{F}=17$ 385 with $\mathrm{P}<0: 01(\mathrm{P}=0: 00)$. It turned out that patients undergoing major surgery experience exyety at 103.73 100.07 Medium,skall amounting to 996.20
\end{abstract}

Keywords: Difference anxious small medium and large operations 


\section{PENDAHULUAN}

Setiap orang pasti pernah mengalami kecemasan pada saat-saat tertentu dan dengan tingkat yang berbeda-beda. Hal tersebut mungkin saja terjadi karena individu merasa tidak memiliki kemampuan untuk menghadapi hal tersebut.

Ramayah (2003) menjelaskan bahwa kecemasan adalah sesuatu yang menimpa hampir setiap orang pada waktu tertentu dalam kehidupannya. Kecemasan merupakan reaksi normal terhadap situasi yang sangat menekan kehidupan seorang. Seseorang akan menderita gangguan cemas manakala yang bersangkutan tidak mampu mengatasi stressor psikososial yang dihadapinya.

Kecemasan sangat berkaitan dengan perasaan tidak pasti dan tidak berdaya. Keadaan emosi ini tidak memiliki objek yang spesifik. Kondisi dialami secara subjektif dan dikomunikasikan dalam hubungan interpersonal. Cemas berbeda dengan rasa takut, yang merupakan penilaian intelektual terhadap sesuatu yang berbahaya. Kecemasan adalah respon emosional terhadap penilaian tersebut (Stuart, 1998).

Branca (1964) menjelaskan bahwa kecemasan juga memiliki orientasi di masa depan. Seseorang mungkin memiliki bayangan bahwa ada bahaya yang mengancam dalam suatu objek. Ia melihat gejala itu ada sehingga ia merasa cemas. Kecemasan ini dibutuhkan agar individu dapat mempersiapkan diri menghadapi peristiwa buruk yang mungkin akan terjadi.

Menurut Atkinson (1990), kecemasan adalah emosi yang tidak menyenangkan dan ditandai dengan istilah-istilah seperti kehawatiran, keprihatinan, dan rasa takut yang kadang-kadang dialami dalam tingkat yang berbeda-beda.

Semakin cemas seorang pasien, menurut psikolog kesehatan Profesor Weinman, luka yang dideritanya juga memerlukan waktu lebih lama untuk sembuh. Sedangkan mereka yang tidak stres pulih dua kali lebih cepat disbanding orang yang stress. Demikian halnya luka dari partisipan yang menceritakan masalah mereka kedalam diari sembuh paling cepat.

Hal ini menunjukkan bahwa melepaskan beban membantu meningkatkan kekuatan fisik. sehat/index.php/read2010/06/10/2704/2/cemasbikin-sakit-sulit-sembuh.
Mansur dan dkk, (dalam Barbara, 2006) mengemukakan bahwa persiapan preoperasi penting untuk memperkecil resiko operasi, karena hasil akhir suatu operasi sangat tergantung pada penilaian keadaan penderita dan persiapan preoperasi. Dalam persiapan inilah ditentukan adanya indikasi atau kontra indikasi operasi, toleransi penderita terhadap tindakan bedah, dan ditetapkan waktu yang tepat untuk melaksanakan pembedahan.

Secara psikologis penderita harus dipersiapkan untuk menghadapi pembedahan karena selalu ada rasa cemas atau rasa takut terhadap penyuntikan, nyeri luka, anastesi, bahkan terhadap kemungkinan cacat atau mati.

Kalau keadaan ini terjadi pada pasien yang akan mengalami operasi dengan pembedahan kulit dan otot, pembiusan secara lokal anastesi, spinal anastesi, dan anastesi umum. Maka kemungkinan akan mengalami kesembuhan yang agak lama.

Bila keadaan cemas terjadi pada operasi besar, dilakukan dengan pembiusan umum, kecemasan yang dialami pasien adalah cemas berat, disini pasien dihadapkan pada rasa takut menghadapi kematian, takut kalau operasi tidak berhasil, takut melihat peralatan-peralatan yang terpasang, takut kalau terjadi cacat, pasien tidak dapat berfikir tenang.

Bila cemas terjadi pada operasi sedang, yang dilakukan dengan cara pembiusan umum atau spinal blok, disini pasien masih bisa melakukan hal-hal yang lebih terarah, memusatkan perhatian pada hal-hal yang penting, dan hanya takut disuntik, kemungkinan cacat ringan. Bila terjadi pada operasi kecil, resiko yang dihadapai adalah rendah, dengan istilah berobat jalan, pembiusan dilakukan dengan cara lokal anastesi, Setiap pasien yang akan diopersi agar tidak mengalami kecemasan yang mengakibatkan gangguan psikologi perlu tindakan pencegahan secara fisik dan fsikologi agar setiap pasien yang akan dioperasi dapat mengatasi kecemasan, rasa takut, ketegangan dan ketidak pastian, dengan cara menjalin hubungan baik antara pasien dengan petugas kesehatan, komunikasi yang efektif antara perawat, dokter dan pasien terutama dalam bidang psikologi, agar pasien yang akan dioperasi dapat mengatasi cemasnya, sehingga setelah operasi pasien dapat sembuh sesuai dengan waktu yang di tentukan. 


\section{BAHAN DAN METODE PENELITIAN}

Adapun variable-variabel yang digunakan dalam penelitian ini, terdiri dari variable-variabel sebagai berikut :

a. Variabel bebas : Jenis operasi ; operasi besar, operasi sedang dan operasi kecil

b. Variabel terikat : Kecemasan

c. Variabel kontrol : Jenis kelamin

Perasaan tidak aman terhadap jenis operasi yang akan dijalani Data tentang kecemasan menghadapi operasi akan diungkap melalui angket yang dibuat sendiri oleh penulis berdasarkan aspek-aspek kecemasan dalam menghadapi operasi.menurut Bukleu yaitu aspek fisiologis dan psikologis.

\section{Populasi dan Teknik Pengambilan Sampel}

Dalam setiap penelitian, masalah populasi dan sample yang dipakai merupakan salah satu faktor penting yang harus diperhatikan. Populasi adalah individu yang bisa dikenai generalisasi dari kenyataan-kenyataan (Hadi, 1987).

Polit dan Hungler (1993) menyatakan bahwa semakin besar sampel yang dipergunakan semakin baik dan representatif hasil yang diperoleh. Dengan kata lain semakin besar sampel semakin mengurangi angka kesalahan. Terdapat beberapa rumus yang dapat dipergunakan untuk menentukan besar sampel.

a. Jika besar populasi $\leq 1000$ maka sampel bisa diambil 20-30\%

b. Jika besar populasi < 1000 maka:

$$
\mathrm{n}=\frac{\mathrm{N} \cdot \mathrm{z}^{2} \mathrm{p} \cdot \mathrm{q} .}{\mathrm{d}(\mathrm{N}-1)+\mathrm{z} \cdot \mathrm{p} \cdot \mathrm{q}}
$$

Populasi dan sampel adalah unsur penting untuk diperhatikan dalam sebuah penelitian. Populasi yang digunakan dalam penelitian ini adalah pasien yang akan menjalani operasi, baik operasi berat, sedang, dan ringan yang jumlahnya belum dapat diprediksi tetapi dari kebiasaan umum dalam satu bulan pasien yang akan menjalani operasi di Rumah Sakit Putri Hijau Medan mencapai 100 orang.

Subjek penelitian yang digunakan dalam penelitian ini adalah :

1. Pasien yang berobat jalan di Rumah Sakit Putri Hijau Medan

2. Pasien yang menjalani operasi besar

\section{Alat Ukur Penelitian}

Instrumen yang dipersiapkan adalah angket kecemasan menghadapi operasi yang disusun berdasarkan aspek-aspek fisiologis dan aspek psikologis.

Angket disusun berdasarkan skala Guttman dengan empat alternatif pilihan. Penelitian yang diberikan dari item yang favourable adalah nilai 4 untuk jawaban selalu, nilai 3 untuk jawaban sering, nilai 2 untuk jawaban kadang-kadang, nilai 1 untuk jawaban tidak pernah. Sementara untuk jawaban Unfavourable nilai 1 untuk jawaban selalu, nilai 2 untuk jawaban sering, nilai 3 untuk jawaban kadang-kadang nilai 4 untuk jawaban tidak pernah.

Tabel 1.Distribusi butir angket kecemasan sebelum uji coba

\begin{tabular}{|c|c|c|c|}
\hline \multirow{2}{*}{$\begin{array}{l}\text { Aspek- } \\
\text { aspek } \\
\text { Kecema- } \\
\text { san }\end{array}$} & \multicolumn{2}{|c|}{ Nomor Butir } & \multirow[b]{2}{*}{ Jumlah } \\
\hline & Favourable & Unfavourable & \\
\hline $\begin{array}{l}\text { Fisiologis } \\
\text { dan } \\
\text { psikologis }\end{array}$ & $\begin{array}{l}1,2,4,5,6, \\
9,10,11, \\
12, \\
13,18,19, \\
23,24,25, \\
26, \\
27,28,29, \\
30,36,37, \\
38, \\
39,40,46, \\
47,48, \\
49,50\end{array}$ & $\begin{array}{l}3,7,8,14, \\
15,16,17, \\
20,21,22, \\
31,32,33, \\
34,35,41, \\
42,43,44,45\end{array}$ & 50 \\
\hline Jumlah & 30 & 20 & 50 \\
\hline
\end{tabular}

\section{Uji Coba Alat Ukur Penelitian}

Pelaksanaan uji coba angket yakni angket kecemasan menghadapi operasi dilakukan mulai tanggal 8 Januari 2017 sampai dengan 5 Februari 2017 pada pasien rawat jalan yang berobat ke poliklinik Rumah sakit, yang akan menjalani operasi di Rumah Sakit Putri Hijau Medan.

Pelaksanaan pengambilan data pada pasien dimulai pada saat pasien diputuskan untuk operasi. Sebelum pelaksanaan operasi harus dipersiapkan terlebih dahulu keadaan umum pasien menjelang hari $(\mathrm{H})$ operasi. Pre operasi adalah merupakan fase awal tindakan pembedahan, dimana dimulai saat diambilnya keputusan bahwa tindakan pembedahan diperlukan dan diahiri sampai pasien dikirim kemeja operasi (Taylor,1977) 
Persiapan pada pasien pre operasi adalah persiapan mental dan persiapan fisik. Persiapan mental adalah pasien harus dipersiapkan untuk menghadapi pembedahan, karena selalu ada cemas atau takut terhadap penyuntikan, nyeri, luka, anesthesia bahka kemungkinan cacat atau meninggal dunia. Sedangkan persiapan fisik yaitu persiapan kulit, diet, pemberian cairan intravena, pengurangan isi perut (klisma), pemberian obatobatan, tes laboratorium, tranfusi dan pemasangan selang kateter kandung kemih (Hidayat, 1977)

Penulis membagikan angket pada pasien yang sedang menghadapi persiapan operasi selama kurang lebih selama satu bulan hingga akhirnya terkumpul pasien sebanyak 45 orang. Setelah angket terkumpul dari 45 pasien yang telah mengisi angketnya sesuai dengan keadaan yang dialami oleh pasien sendiri dan dikumpulkan setelah diisi oleh pasien masing-masing kemudian penulis mewawancarai pasien dan keluarga pasien pada saat pengembalian angket tersebut. Angket diisi sesuai dengan petunjuk yang diberikan terhadap pasien, selanjutnya dilakukan penilaian terhadap butir angket dengan cara membuat format nilai berdasarkan skor-skor yang ada pada setiap lembarnya, kemudian skor yang merupakan pilihan subjek pada setiap butir pernyataan akan dipindahkan kekertas millimeter yang diformat sesuai dengan keperluan tabulasi data, yaitu lajur untuk nomor pernyataan dan baris untuk nomor subjek.

Berdasarkan hasil uji coba angket kecemasan menghadapi operasi menunjukkan bahwa dari 50 butir yang tersebar terdapat 4 (empat) butir yang gugur yakni butir nomor 7, 16, 21,23 pada angket kecemasan mengh adapi operasi, sedangkan butir yang valid berjumlah 46 butir memiliki koefisien daya beda yang bergerak yakni antara 0.315 sampai dengan 0.969 .

Setelah butir dianalisis dengan tehnik anava satu jalur kemudian dilanjutkan dengan analisis keandalan (reliabilitas). Tehnik uji reliabilitas angket kecemasan menghadapi operasi dengan menggunakan pendekatan alpha Cronbach.. Diketahui indek reliabilitas sebesar 0.969.

Dengan demikian angket yang telah disusun dalam penelitian ini memiliki tingkat keterandalan yang tinggi (sangat reliable) yaitu dapat juga dikatakan keterpercayaan, keterandalan, keajegan, kestabilan, konsistensi, dan sebagainya. Hasil pengukuran dapat dipercaya apabila dalam beberapa kali pelaksanaan pengukuran terhadap sekelompok subjek yang sama, diperoleh hasil yang relatif sama selama aspek dalam diri subjek yang diukur belum berubah.

\section{Pelaksanaan Penelitian}

Pelaksanaan penelitian dilaksanakan selama satu bulan yakni pada tanggal 8 Januari 2017 sampai dengan 5 Februari 2017. Dalam penelitian ini jumlah subjek yang digunakan adalah yang digunakan adalah sebanyak 45 orang. Pada tahap awal penulis memberikan uraian mengenai maksud dan tujuan diadakannya penelitian, kepada masing-masing responden. Agar angket ini dapat diisi dengan tenang, maka angket akan ditinggalkan untuk diambil kembali keesokan harinya setelah angket diisi dan ada juga yang langsung diberikan karena besoknya pasien tidak datang.

\section{Analisis Data Dan Hasil Penelitian}

Teknik analisis data yang digunakan dalam penelitian ini adalah tehnik analisis anava satu jalur. Hal ini dilakukan sesuai judul penelitian dan identifikasi variabel-variabelnya, dimana analisis anava satu jalur dapat digunakan untuk menganalisis perbedaan antara menghadapi operasi besar, sedang, kecil hubungannya dengan kecemasan, maka data yang telah diperoleh harus dilakukan uji asumsi antara lain uji normalitas sebaran dan uji homogenitas kelompok dan uji beda.

1.Uji asumsi

a. Uji normalitas Sebaran

Adapun maksud dari uji normalitas sebaran ini adalah untuk membuktikan bahwa penyebaran data-data penelitian yang menjadi pusat perhatian telah menyebar berdasarkan prinsif kurve normal.

Berdasarkan uji normalitas sebaran dengan perhitungan Kosmograv-Smirnof menunjukkan bahwa data penelitian yang dianalisis memiliki sebaran yang normal yang ditunjukkan koefisien K-S sebasar 0. 122 dengan $\mathrm{p}$ $>0.05(\mathrm{p}=0.089)$.

Selanjutnya perhitungan homogenitas kelompok menunjukkan bahwa ketiga kelompok yang digunakan dalam penelitian ini adalah homogen, yang ditunjukkan oleh koefisien homogenitas sebesar 2.724 dengan $\mathrm{p}>0.05$ ( $\mathrm{p}=$ 0.077). 


\section{Uji beda}

Analisis data yang digunakan adalah analisis statistic anava satu jalur, ternyata ada perbedaan kecemasan yang sangat signifikan diantara pasien yang menghadapi operasi operasi besar, sedang, kecil; yang ditunjukkan oleh koefi sien $\mathrm{F}=17.385$ dengan $\mathrm{p}<0.01(\mathrm{p}=0.00)$. Ternyata pasien yang menjalani operasi besar mengalami kecemasan yang lebih tinggi dibanding dengan pasien yang menjalani operasi sedang dan kecil. Pada pasien yang akan menjalani operasi besar memiliki kecemasan sebesar 103.73, pasien yang menjalani operasi sedang memiliki kecemasan sebesar 100.07, dan pasien yang menjalani operasi kecil memiliki kecemasan.

\section{Pembahasan}

Gorzeman dan Bawobin (1991) menemukan sejumlah 97,6 \% pasien yang akan menjalani operasi besar mengalami susah tidur/gangguan tidur, hal tersebut selalu dikenal dengan stress psikologi yang penyebabnya adalah kecemasan. Kondisi ini mengharuskan pihak para medis harus mempersiapkan preoperasi terdiri dari persiapan fisik dan persiapan psikologis pasien. Sementara pasien yang akan menjalani operasi sedang juga mengalami hal yang sama, meski jumlah persentasenya belum pernah dikemukakan, dan pada pasien yang akan menjalani operasi kecil merasa mengalami kecemasan.

Setiap pasien yang akan diopersi agar tidak mengalami kecemasan yang mengakibatkan gangguan psikologi perlu tindakan pencegahan secara fisik dan fsikologi agar setiap pasien yang akan dioperasi dapat mengatasi kecemasan, rasa takut, ketegangan dan ketidak pastian, dengan cara menjalin hubungan baik antara pasien dengan petugas kesehatan, komunikasi yang efektif antara perawat, dokter dan pasien terutama dalam bidang psikologi, agar pasien yang akan dioperasi dapat mengatasi cemasnya, sehingga setelah operasi pasien dapat sembuh sesuai dengan waktu yang di tentukan.

\section{KESIMPULAN}

Berpedoman pada hasil-hasil penelitian yang telah diperoleh maka berikut ini dapat disimpulkan hal-hal sebagai berikut:

1. Ada perbedaan kecemasan kecemasan yang sangat signifikan diantara pasien yang akan menjalani operasi besar, sedang, dan kecil yang ditunjukkan oleh koefisien $\mathrm{F}=17.385$ dengan $\mathrm{p}<0.01(\mathrm{p}=0.00)$

2. Ternyata pasien yang menghadapi operasi besar mengalami kecemasan yang lebih tinggi dibandingkan dengan pasien yang menjalani operasi sedang dan ringan hal ini di tunjukkan oleh rata-rata kecemasan yang dimiliki oleh masing-masing kelompok yaitu:

a. Operasi besar $=103.73$.

b. Operasi sedang $=100.07$

c. Operasi kecil $=96.20$

Berdasarkan hasil analisis ini ada perbedaan kecemasan yang signifikan ini disebabkan oleh setiap pasien yang akan menjalani operasi besar takut akan pembiusan dan rasa takut akan kematian, takut kalau operasi tidak berhasil, takut cacat serta pasien tidak dapat berfikir tenang. Pada pasien yang mengalami operasi sedang merasa takut disuntik, takut cacat ringan, takut sakit pada luka operasi, serta opersi kecil mereka merasa takut disuntik, sakit pada luka operasi.

Dalam hal ini dapat penulis simpulkan semakin besar operasi yang dihadapi pasien semakin merasa cemas dan telihat juga pana hasil analisis pada anova satu jalur.

\section{SARAN}

1. Saran kepada perawat

Mengacu pada hasil penelitian yang telah diperoleh dalam penelitian ini, dimana dinyatakan bahwa ada, perbeaan kecemasan dalam menghadapi operasi. Kecemasan pada operasi besar lebih tinggi dibandingkan kecemasan pada operasi sedang dan keccil. Maka perawat dharapkan mampu memberikan dorongan yang positif yaitu melepaskan beban, menghilangkan stress, dan mencurahkan perasaan takut pasien kepada perawat, karena ini dapat membantu meningkatkan kekuatan fisik dan psikologis serta mempercepat penyembuhan luka.

\section{Saran kepada peneliti selanjutnya}

Berdasarkan hasil-hasil yang telah diketahui, peneliti menyarankan kepada peneliti selanjutnya, untuk dapat mengembangkan penelitian tentang perbedaan kecemasan menghadapi operasi ini.

\section{DAFTAR PUSTAKA}

Arikunto, S. 1984. Prosedur Penelitian Suatu Pendekatan Praktis. Jakarta, Bina Aksara. 
Atkinson, Rita L. 1987. Pengantar Psikologi Edisi Kesebelas Jilid 2.

Azwar, S. 2006. Penyusunan Skala Psikologi. Pustaka Pelajar.

Bowobin, G. 1991. Medeikal Surgical Nursing. Toronto. Philadelpia, BC. Deeker

Dinas Kesehatan, 2004. Majalah kesehatan. Jakarta. EGC.

Darajat, Z. 1990. Kesehatan Mental. Jakarta, Bulan Bintang.

Gruendemann J.B. 2006. Buku Ajar Keperawatan Pre Operatif Volume I. Penerbit Buku Kedokteran. EGC.

Gurning, F.P. 2017. Pembinaan Puskesmas Terhadap Pelaksanaan Program Usaha Kesehatan Sekolah Di Wilayah Kerja Puskesmas Padang Matinggi Kota Padangsidimpuan. Jurnal Ilmiah Penelitian Kesehatan (Jumantik). http://jurnal.uinsu.ac.id/index.php/kesmas/arti cle/view/1190 Tanggal Akses 2 Agustus 2017.

Gurning, F.P. 2017. Pengaruh Karakteristik Kader Terhadap Keaktifan Kader Posyandu Di Desa Bahung Sibatu-Batu Kecamatan Sei Dadap Kabupaten Asahan. Jurnal Ilmiah Penelitian Kesehatan (Jumantik). http://jurnal.uinsu.ac.id/index.php/kesmas/arti cle/view/1191 Tanggal Akses 2 Agustus 2017.

Guyton, H. 1997. Buku Ajar Fisiologi Kedokteran. Jakarta. EGC.
Hadi, S. 1987. Metode Riserch. Yokyakarta. Penerbit Yayasan Fakultas Psikologi.

Hawari, D. 2010. Psikiater. Manajemen Stres Cemas dan Depresi, Fakultas Kedoktran Universitas Indonesia.

Hariyono, R. 2000. Mengatasi rasa cemas. Jatim. Pustaka Belajar.

Jersild, A.T. 1965. The Psychology Of Adolesence. Znd. New York. The Memilland Company

Oswari. E, 2000 Bedah dan Perawatannya Balai Penerbit Fakultas Kedokteran Universitas Indonesia.

Pratama, M.Y. 2017. Analisis Kualitas Kehidupan Kerja Perawat Pelaksana di Rumah Sakit Putri Hijau Medan. Jurnal Ilmiah Penelitian Kesehatan (Jumantik). http://www.jurnal.uinsu.ac.id/index.php/kesm as/article/view/1192, tanggal akses 1 Agustus 2017.

Pratama, M. Y. 2012. Pengaruh Quality of Work Life Terhadap Kinerja Perawat Pelaksana di Rumah Sakit Tk II Putri Hijau Kesdam I/BB Medan. Universitas Sumatera Utara. Medan.

Tarmiji, 1982. Kesehatan Jiwa. Jakarta. Bulan Bintang.

Tomb, D.A, 2004. Buku Saku Psikiatri Edisi 6 Penerbit Buku Kedokteran EGC. 